\title{
miR-212-5p attenuates ferroptotic neuronal death after traumatic brain injury by targeting Ptgs2
}

\author{
Xiao Xiao ${ }^{1 \dagger}$, Youjing Jiang ${ }^{1 \dagger}$, Weibo Liang ${ }^{1}$, Yanyun Wang ${ }^{2}$, Shuqiang Cao ${ }^{1}$, He Yan $^{3}$, Linbo Gao ${ }^{2 *}$ and \\ Lin Zhang ${ }^{1,2^{*}}$
}

\begin{abstract}
Ferroptosis, a newly discovered form of iron-dependent regulated cell death, has been implicated in traumatic brain injury (TBI). MiR-212-5p has previously been reported to be downregulated in extracellular vesicles following TBI. To investigate whether miR-212-5p is involved in the ferroptotic neuronal death in TBI mice, we first examined the accumulation of malondialdehyde (MDA) and ferrous ion, and the expression of ferroptosis-related molecules at $6 \mathrm{~h}, 12 \mathrm{~h}, 24 \mathrm{~h}, 48 \mathrm{~h}$ and $72 \mathrm{~h}$ following controlled cortical impact (CCl) in mice. There was a significant upregulation in the expression of Gpx4 and Acs/4 at $6 \mathrm{~h}$, Slc7a11 from $12 \mathrm{~h}$ to $72 \mathrm{~h}$, and Nox2 and Sat1 from $6 \mathrm{~h}$ to $72 \mathrm{~h}$ post injury. Similarly, an upregulation in the expression of Gpx4 at $6 \mathrm{~h}$, Nox2 from $6 \mathrm{~h}$ to $72 \mathrm{~h}, \mathrm{xCT}$ from $12 \mathrm{~h}$ to $72 \mathrm{~h}$, and Sat 1 at $72 \mathrm{~h}$ after $\mathrm{CCl}$ was observed at the protein level. Interestingly, MDA and ferrous ion were increased whereas miR-212-5p was decreased in the CCI group compared to the sham group. Furthermore, we found that overexpression of miR-212-5p attenuated ferroptosis while downregulation of miR-212-5p promoted ferroptotic cell death partially by targeting prostaglandin-endoperoxide synthase-2 (Ptgs2) in HT-22 and Neuro-2a cell lines. In addition, administration of miR-212-5p in CCl mice significantly improved learning and spatial memory. Collectively, these findings indicate that miR-212-5p may protect against ferroptotic neuronal death in $\mathrm{CCl}$ mice partially by targeting Ptgs2.
\end{abstract}

Keywords: Traumatic brain injury (TBI), Ferroptosis, miR-212-5p, Prostaglandin endoperoxide synthase-2 (Ptgs2)

\section{Introduction}

Traumatic brain injury (TBI) is defined as an alteration in brain morphology or a disruption in brain function resulting from an external force [1]. As a major public health problem of substantial proportion, TBI and its complications have become a huge burden to individuals, families and society in general [2-5]. It is reported that there are more than 50 million new TBI cases occurring annually, and TBI survivors have a pooled standardized mortality

\footnotetext{
* Correspondence: gaolinboscu@163.com; zhanglin@scu.edu.cn

${ }^{+}$Xiao Xiao and Youjing Jiang contributed equally to this work.

${ }^{2}$ Laboratory of Molecular Translational Medicine, Center for Translational Medicine, Key Laboratory of Birth Defects and Related Diseases of Women and Children (Sichuan University), Ministry of Education, West China Second University Hospital, Sichuan University, Chengdu, Sichuan, People's Republic of China

${ }^{1}$ Department of Forensic Genetics, West China School of Basic Medical Sciences \& Forensic Medicine, Sichuan University, Chengdu 610041, Sichuan, People's Republic of China

Full list of author information is available at the end of the article
}

ratio of 2.18 (95\% CI 1.88-2.52) according to the global burden of disease (GBD) studies [6]. However, the knowledge development has not caught up with the rising worldwide burden of TBI, most attempts at new medical interventions have failed to show superior efficacy compared with conventional therapies [7]. Thus, both clinical and experimental studies are needed to better understand the mechanism of TBI.

Ferroptosis is a recently recognized type of nonapoptotic cell death which occurs as a consequence of lethal lipid peroxidation [8]. Amino acid, lipid, and iron metabolism are intimately involved in determining cellular sensitivity to the initiation and execution of ferroptosis [8]. Diverse stresses destabilize these metabolic processes, and induce excessive intracellular accumulation of ROS that culminates in the collapse and rupture of the membrane structure of cellular organelles, such as mitochondria, endoplasmic reticulum [9], and lysosome

(c) The Author(s). 2019 Open Access This article is distributed under the terms of the Creative Commons Attribution 4.0 International License (http://creativecommons.org/licenses/by/4.0/), which permits unrestricted use, distribution, and 
[10]. Recent studies have identified a connection between ferroptosis and the pathophysiology of acute organ damage, like acute lung injury (ALI), acute kidney injury (AKI), and TBI $[11,12]$. More importantly, it has been implicated in the pathological process associated with neurodegenerative diseases [13] for which TBI might represent a potential risk factor [14-16]. Given that ferroptosis might be involved in the development of TBI, new approaches, aiming to block ferroptosis-related brain cell death, may help minimize the risk of TBI and maximize chances of recovery.

MicroRNAs (miRNAs) are single stranded RNAs (20-24 nucleotides) that negatively regulate gene expression by binding to the 3 '-untranslated region (UTR) of specific target mRNAs, which results in inhibition of mRNA translation or direct degradation of the mRNA [17]. MiRNAs have been shown to be induced by TBI and therefore may offer therapeutic potential [18]. Previous studies have demonstrated that miR-212 is highly expressed in the brain [19] where it may play a role in synaptic plasticity [20], memory formation [21, 22], and blood brain barrier integrity [23]. Meanwhile, this conserved miRNA was shown to be downregulated in Alzheimer's disease (AD), and the tau protein level was increased in the brain of miR-212 knockout mice $[24,25]$. Importantly, miR-212-5p has been reported to be down-regulated in the extracellular vesicles following controlled cortical injury (CCI) [26].

Here, we first set out to demonstrate the occurrence of ferroptosis in TBI through assessing related molecules and investigating iron and malondialdehyde accumulation after TBI. Subsequently, we discovered that miR212-5p was significantly downregulated after TBI and functionally suppressed ferroptosis by directly targeting Ptgs2. Moreover, we tested the efficacy of miR-212-5p agomir in alleviating the neurobehavioral deficits following TBI in mice. These findings highlight the significance of ferroptosis in TBI and introduce miR-212-5p as a critical regulator of ferroptosis.

\section{Materials and methods}

\section{Animals and ethics statement}

Adult male C57BL/6 J mice, aged 10-12 weeks and weighing 20 to $24 \mathrm{~g}$, were kept in individually ventilated cages receiving food and water ad libitum for at least 7 days prior to operation under standard conditions $(12 \mathrm{~h}$ light/dark cycle, $22-25^{\circ} \mathrm{C}, 50 \%$ relative humidity). Food was withheld overnight prior to operation. All procedures were approved by the Animal Care and Experimental Committee of Sichuan University.

\section{CCI model}

Mice were subjected to a CCI with craniotomy as previously described [27-29]. Briefly, following anesthesia with isoflurane $(4 \%$ for induction and $1-2 \%$ for maintenance), mice were mounted on a stereotaxic frame. A midsagittal incision was performed in the scalp under sterile conditions and a $4.5 \mathrm{~mm}$ diameter circular craniotomy was made over the left parietotemporal cortex with a burr drill. Then, the skullcap was gently removed and a $3.0 \mathrm{~mm}$ diameter round and flat tip was carefully placed vertically to the dural surface. The electromagnetic controlled cortical impact device was set to $5.0 \mathrm{~m} / \mathrm{s}$ for strike velocity, $2.0 \mathrm{~mm}$ for strike depth and $100 \mathrm{~ms}$ for dwell time. A sterile plastic film covered the bone window and intermittent sutures of the skin, and disinfection with iodophor were performed. The entire procedure required 15-30 min per mouse. Mice with dural lacerations were removed. After a certain survival period, the mice were anesthetized and perfused transcardially with $10 \mathrm{ml}$ of isotonic saline. The ipsilateral cortex around the injury site was rapidly dissected and stored at $-80^{\circ} \mathrm{C}$. In total, 180 mice were randomly divided into two groups: the CCI group; and the sham group that underwent craniotomy without injury. Among them, 150 samples were each cut into two identical pieces (total $=300$ pieces) and used for qRT-PCR $(n=90$ pieces), Western blotting ( $n=50$ pieces), iron ( $n=60$ pieces), and MDA assay ( $n=60$ pieces); the remaining tissues were stored and used for other experiments, while 30 mice were assigned to perform the Morris water maze (MWM) test. Four dead or model failure mice were excluded (CCI: 2/90; sham: 2/90).

\section{Iron assay}

Ferrous ion $\left(\mathrm{Fe}^{2+}\right)$ level in tissues were estimated by the iron assay kit (\#ab83366, Abcam, Cambridge, Mass, USA) according to the manufacturer's instructions. In brief, after washing in ice-cold PBS, tissue samples were weighed and homogenized in 4-10 X volumes of iron assay buffer. Then, iron reducer was added to each supernatant. The mixture was incubated for $30 \mathrm{~min}$, and the output was promptly assessed on a colorimetric microplate reader $(\mathrm{OD}=593 \mathrm{~nm})$. The $\mathrm{Fe}^{2+}$ level was normalized to the weight of the tissue samples.

\section{MDA assay}

The content of MDA in tissue samples was determined using a Lipid Peroxidation (MDA) Assay Kit (\#S0131, Beyotime, Haimen, Jiangsu, China) according to the manufacturer's instructions. In brief, the tissue samples were weighed and homogenized in ice-cold PBS containing 1\% phenylmethanesulfonyl fluoride (PMSF) on ice. Tissue lysates were then centrifuged at $12,000 \mathrm{~g}$ for $15 \mathrm{~min}$ at $4{ }^{\circ} \mathrm{C}$ to collect the supernatant. The MDA in the sample reacted with thiobarbituric acid (TBA) to generate an MDA-TBA adduct that was colorimetrically quantified $(\mathrm{OD}=532 \mathrm{~nm})$. 
The MDA level was normalized to the weight of tissue samples.

\section{Chemicals and antibodies}

Rsl3 (\#S8155) and ferrostatin-1 (Fer-1, \#S7243) were purchased from Selleck Chemicals (Houston, TX, USA), while Necrosulfonamide (ab143839) and ZVAD-FMK (ab120382) were purchased from Abcam (Cambridge, Mass, USA). The antibodies used in this study were as follows: Gpx4 (ab125066, Abcam, Cambridge, Mass, USA), Acsl4 (ab137525, Abcam), xCT (ab175186, Abcam), Nox2 (Cybb, ab80508, Abcam), Sat1 (PA1-16992, Thermo, Rochester, NY, USA), Actb (Lot\#Nb15, Absin, Shanghai, China). HRP-conjugated secondary antibody was obtained from ZSGB-BIO (Beijing, China).

\section{Cell culture}

The immortalized mouse hippocampal neuron line (HT22) and the mouse neuroblastoma cell line (Neuro2a) were obtained from Honsun Biological Technology (Shanghai, China) and were cultured in Dulbecco's Modified Eagle's Medium (DMEM, Hyclone, Utah, USA) supplemented with $10 \%$ fetal bovine serum (Hyclone, Utah, USA), and $1 \%$ penicillin-streptomycin.

\section{RNA extraction, CDNA synthesis and real-time PCR analysis}

Quantitative real-time PCR (qRT-PCR) was performed to assess the expression level of miR-212-5p and the mRNA expression of the ferroptosis-related molecules Gpx4, Acsl4, Slc7a11, Nox2, Sat1, Ptgs2 at $6 \mathrm{~h}, 12 \mathrm{~h}$, $24 \mathrm{~h}, 48 \mathrm{~h}$, and $72 \mathrm{~h}$ following CCI. In brief, total RNA was prepared from cortical tissue samples using the Trizol reagent (Invitrogen, Carlsbad, CA, USA). The cDNA synthesis was achieved with RevertAid First Strand cDNA Synthesis Kit (\#K1621, Thermo Scientific, USA) after determining the quantity of total RNA with a NanoDrop ND-1000 (NanoDrop, Wilmington, DE). qRT-PCR using the SYBR ${ }^{\mathrm{mi}}$ Green PCR Master Mix (\#43091055, ThermoFisher, USA) was then conducted on a Life Technologies Prism 7500 instrument (Life Technologies, Foster City, CA, USA). For the microRNA, a similar procedure was performed except that the cDNA synthesis and qRT-PCR was conducted applying miDETECT A Track $^{\text {Tw }}$ miRNA qRT-PCR Starter Kit (\#R11068.5, RiboBio, Guangzhou, Guangdong, China). $\beta$-actin (Actb) and noncoding small nuclear RNA (U6) were applied as internal controls respectively to normalize the data. The primers are available upon request.

\section{Western blotting}

Cortical tissue samples were isolated and lysed in RIPA reagent (Beyotime, Haimen, Jiangsu, China) containing 1\% PMSF (Beyotime, Haimen, Jiangsu, China). BCA assay kit (Beyotime, Shanghai, China) was then used to quantified the total protein extraction. Protein samples were separated on a $10 \%$ SDS polyacrylamide gel by electrophoresis, and then electro-transferred onto polyvinylidene difluoride membranes (Bio-Rad Laboratories, Hercules, CA, USA). The membranes were incubated with primary antibodies at $4{ }^{\circ} \mathrm{C}$ overnight after blocking with bovine serum albumin at room temperature for $1 \mathrm{~h}$. The membranes were then incubated with secondary antibodies after washing in Tris-buffered saline with Tween 20 (TBST). Finally, signals were visualized by an ECL kit (Merck millipore, Massachusetts, USA). NIH Image J software (Bethesda, MD, USA) was applied to quantify the band density, while $\beta$-actin was used as the loading control.

\section{Mimic, inhibitor and transfection}

The mmu-miR-212-5p mimic, inhibitor and their negative controls were purchased from RiboBio (\#R10034.8, Guangzhou, Guangdong, China). Cells were dissociated using $0.05 \%$ trypsin and counted with a Neubauer hemocytometer. Transfections were performed according to the manufacturer's instructions with Lipofectamine 3000 (L3000015, Invitrogen, Carlsbad, CA, USA). Briefly, the mimic, inhibitor $(20 \mu \mathrm{M})$ and transfection reagent were diluted in Opti-MEM medium. After mixing and incubating at room temperature for $15 \mathrm{~min}$, the solution was transfected into HT22 and Neuro-2a cells.

\section{Cell death assay}

Lactate dehydrogenase (LDH) activity was measured to determine the cell death using the Cytotoxicity Detection Kit (\#G1780, Promega, Madison, Wi, USA). Prior to treatment, cells were planted into 96 well culture plate and Rsl3 was applied at a final concentration of $3 \mu \mathrm{M}$ in the culture medium for $24 \mathrm{~h}$. To elucidate the specific induction of ferroptosis, different cell death inhibitors combined with RSL3 were used, including ferrostatin-1, necrosulfonamide, and zVAD-fmk. Incubation conditions: ferrostatin- $1,1 \mu \mathrm{M}$; zVAD-fmk, $10 \mu \mathrm{M}$; and necrosulfonamide, $0.5 \mu \mathrm{M}$.

\section{Plasmid construction and luciferase reporter assay}

The 3'-UTR of Ptgs 2 mRNA with potential target sites of miR-212-5p was amplified through PCR from gDNA. The amplicon was inserted into a pGL3 basic vector with $X b a \mathrm{I}$ and Xho I restriction enzyme sites (Promega, Madison, WI, USA) (forward primer, 5'-ACTCGAGGCCAGTGAGAA GGGAAATGA-3' and reverse primer, 5' -CCTCTAGATG AACTTGGACCCCTTTGTT-3'). Subsequently, plasmid DNA (pGL3-Ptgs2-wt) was isolated from recombinant 
colonies and verified by sequencing. To generate the 3'UTR mutants of Ptgs2 (pGL3-Ptgs2-mt), the binding site (CCAAGG) was altered to (TGCCAC) using the sitedirected mutagenesis kit (NEB E0554, Grand Island, Nebraska, USA), and sequenced to guarantee its authenticity. HT22 and Neuro-2a cells were co-transfected with empty, wild-type (pGL3-Ptgs2-wt) or mutant-type (pGL3Ptgs2-mt) reporter vectors and miR-212-5p mimic by Lipofectamine 3000 reagent. Obtained $48 \mathrm{~h}$ after transfection, cells were examined with the dual-luciferase reporter assay (Cat. \#E1960, Promega, Madison, Wi, USA). Three independent experiments with at least two replicates were applied and Renilla luciferase was used to normalize the transfection efficiency.

\section{Intracerebroventricular injection (ICV)}

The agomir and negative control (NC) were purchased from RiboBio (Guangzhou, Guangdong, China). Anesthetized mice were placed in the stereotaxic frame. With a 5- $\mu$ l-gauge hamilton-syringe, $10 \mu \mathrm{l}$ of $5 \mathrm{nM}$ agomir or $\mathrm{NC}$ were stereotactically delivered into the right lateral ventricle at $1 \mu \mathrm{l} / \mathrm{min}$ for $10 \mathrm{~min}$. The syringe was positioned at the following coordinates: AP $-0.3 \mathrm{~mm}, \mathrm{ML}+0.9 \mathrm{~mm}$, and DV $-2.8 \mathrm{~mm}$. On the 4th and 2nd day prior to TBI, the agomir or NC was consecutively injected in order to ensure adequate concentration and efficacy.

\section{Morris water maze}

To evaluate memory and spatial learning of mice following CCI, the MWM test was performed as previously described [30, 31]. A plastic tank $(85 \mathrm{~cm}$ in diameter and $60 \mathrm{~cm}$ in height) located in a room with four visual cues was filled with water $\left(23^{\circ} \mathrm{C} \pm 1{ }^{\circ} \mathrm{C}\right)$ to a height of $30 \mathrm{~cm}$. The MWM test began on the 7 th day following CCI. Briefly, mice were individually placed in the apparatus in one of the four different quadrants and allowed up to 60 s to reach the submersed platform in the place navigation test. Mice were guided to the submersed platform if they failed to find it, and all of them were allowed to remain on the platform for an additional 10s. The behavioral data were automatically recorded and studied using a video tracking system (\#WMT-100S, Techman soft, Chengdu, Sichuan, China). On the 15th day, the spatial probe test was conducted without the hidden platform. During the test, the frequency of crossing the platform location was recorded and analyzed by the same video computer system.

\section{Statistical analyses}

Data are presented as means \pm standard error of the mean (SEM). A Student's $t$-test was used to compare means of the two groups. One-way analysis of variance (ANOVA) was used for comparisons among multiple groups and Tukey's post hoc test was applied to identify specific differences between groups, while the data of escape latency was analyzed using repeated-measures twoway analysis of variance (ANOVA). All data analysis was done using GraphPad Prism 7.0 (GraphPad Software, Inc., Cary, $\mathrm{NC}$ ). A value of $p<0.05$ is considered to be statistically significant.

\section{Result}

$\mathrm{CCl}$ is followed by changes in lipid formation, ferrous ion levels and expression of ferroptosis-related molecules

MDA is an end-product of polyunsaturated fatty acid peroxidation, while the level of $\mathrm{Fe}^{2+}$ reflects the iron overload which has the potential to generate highly reactive hydroxyl radicals through the fenton reaction [32]. We firstly demonstrated CCI results in the accumulation of these two markers. As shown in Fig. 1a and b, both the levels of ferrous ion and MDA were significantly elevated at $6 \mathrm{~h}, 12 \mathrm{~h}, 24 \mathrm{~h}, 48 \mathrm{~h}$, and $72 \mathrm{~h}$ post injury. The genes essential for ferroptosis regulation were selected to evaluate mRNA and protein levels using qRT-PCR and Western-blotting, including Gpx4 (protects cells against membrane lipid peroxidation), Acsl4 (related to the generation of lipid peroxidation products), $\mathrm{xCT}$ (a sodium-independent cystine-glutamate antiporter) and Sat1 (involved in p53-mediated ferroptosis). The mRNA levels of Gpx4 (Fig. 1c) and Acsl4 (Fig. 1d) were upregulated at $6 \mathrm{~h}$ post injury, while the mRNA levels of $S l c 7 a 11$ (Fig. 1e) were upregulated from $12 \mathrm{~h}$ to $72 \mathrm{~h}$ post injury. The mRNA levels of Nox2 (Fig. 1f) and Sat1 (Fig. 1g) were constantly upregulated from $6 \mathrm{~h}$ to $72 \mathrm{~h}$. The protein levels were also observed to be significantly upregulated, with Gpx4 at $6 \mathrm{~h}$, Nox2 from $6 \mathrm{~h}$ to $72 \mathrm{~h}, \mathrm{xCT}$ from $12 \mathrm{~h}$ to $72 \mathrm{~h}$, and Sat1 at $72 \mathrm{~h}$ following CCI (Fig. 2).

\section{MiR-212-5p is downregulated after TBI and regulates Rsl3-induced ferroptosis in HT22 and neuro-2a cells}

Previous studies have reported that CCI significantly decreased the level of miR-212-5p in the extracellular vesicles of brain tissue. We confirmed that the expression of miR-212-5p was constantly downregulated at $6 \mathrm{~h}, 12 \mathrm{~h}$, $24 \mathrm{~h}, 48 \mathrm{~h}, 72 \mathrm{~h}$ after TBI (Fig. 3a), and the reduction was significant, for its expression was shrunk, on an average, by $66 \%$ relative to the sham group at most indicated time points.

To elucidate whether miR-212-5p can influence ferroptotic neuronal death, we first assessed the ferroptosisinducing activity of Rsl3 in HT-22 and Neuro-2a cell lines. Rsl3 successfully induced cell death in both cell lines and this process was reversed by using the inhibitor of ferroptosis, Fer-1 (Fig. 3b). Contrarily, no reverse effects were observed on Rsl3-induced cell death with treatment of the apoptosis inhibitor zVAD-fmk or necroptosis inhibitor necrosulfonamide (Fig. 3b). Taken together, these findings 

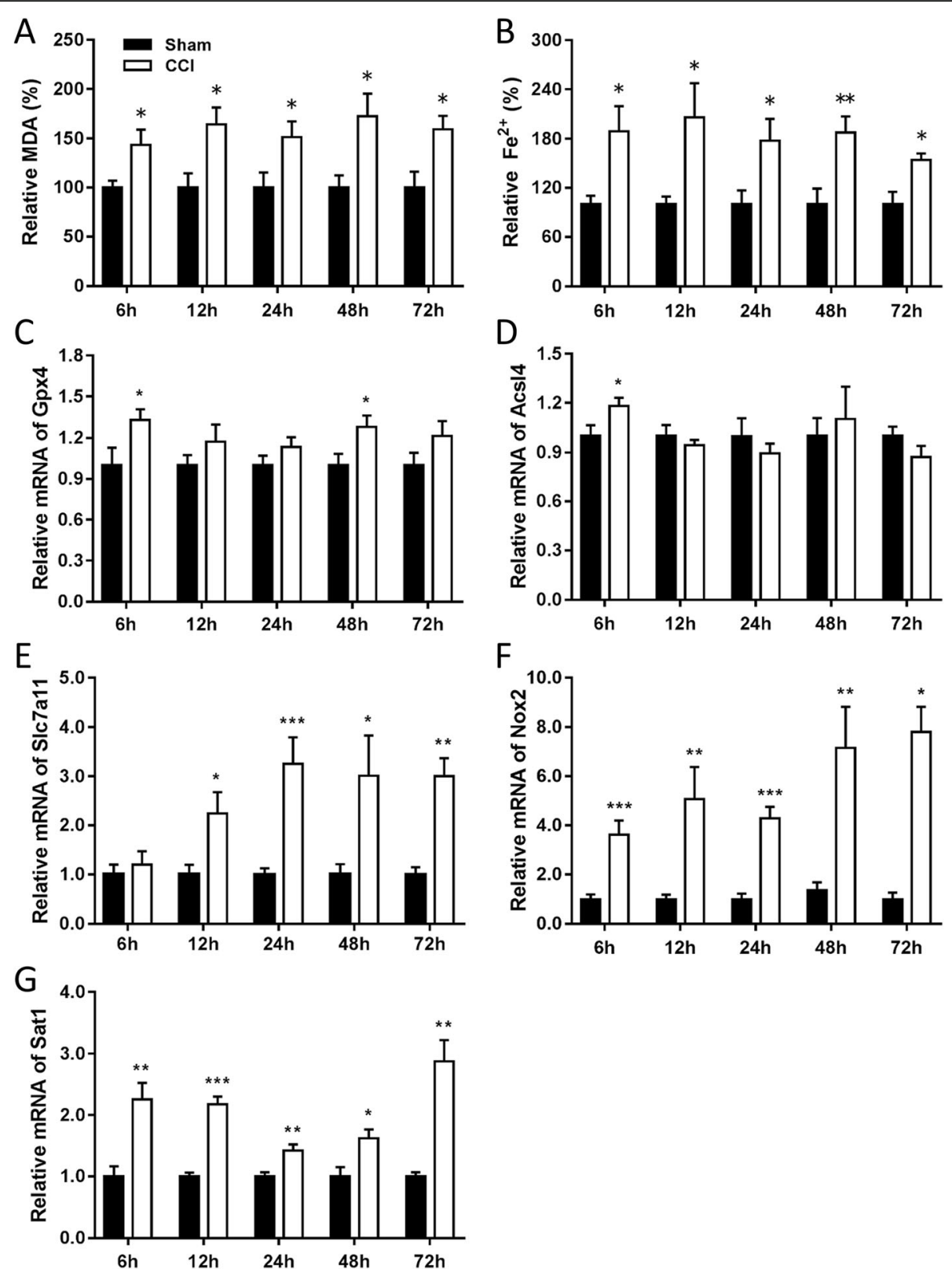

Fig. 1 The concentration of MDA and $\mathrm{Fe}^{2+}$ and the mRNA levels of ferroptosis-related molecules following CCl. MDA (a) and Fe ${ }^{2+}$ (b) levels in the ipsilateral cortex at $6 \mathrm{~h}, 12 \mathrm{~h}, 24 \mathrm{~h}, 48 \mathrm{~h}$, and $72 \mathrm{~h}$ after $\mathrm{CCl}(\mathrm{n}=6$ for each group). Quantitative RT-PCR showing the relative expression levels of Gpx4 (c), Acs/4 (d), S/c7a11 (e), Nox2 (f), Sat1 (g) in the cortex at the indicated times after injury ( $n=9$ for each group). Data are expressed as mean \pm SEM. Data were analyzed using the student's $t$-test. ${ }^{*} p<0.05,{ }^{* *} p<0.01,{ }^{* * *} p<0.001$. MDA, malondialdehyde; $C C l$, controlled cortical impact; $\mathrm{Fe}^{2+}$, ferrous ion

imply that ferroptosis can be sufficiently induced by Rsl3 in both HT-22 and Neuro-2a cell lines.

Thereafter, we overexpressed miR-212-5p by transfecting HT-22 and Neuro-2a cells with a miR-212-5p mimic (Fig. 3c) and suppressed it by applying a miR-212-5p inhibitor (Fig. 3d). Compared to the cells transfected with the mimic negative control, overexpression of miR-212$5 p$ decreased the cell death rate (Fig. 3e) while suppression of miR-212-5p expression increased the cell death rate (Fig. 3f). These results indicate that miR-212-5p plays a critical role in regulating ferroptosis in HT-22 and Neuro-2a cells.

\section{MiR-212-5p negatively regulates Ptgs2}

To identify a specific target of miR-212-5p that may be implicated in both the ferroptosis pathway and the pathological process of TBI pathway, we investigated mRNAs that are differentially expressed following TBI from a publicly available 
A

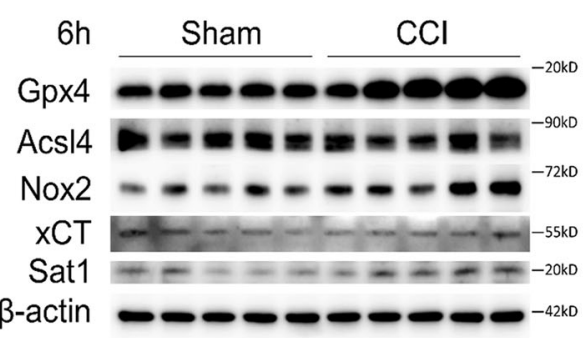

B

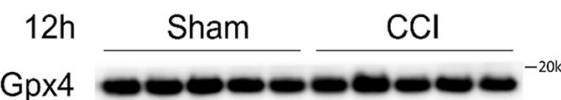

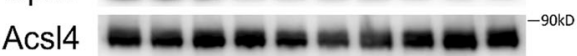

Nox2

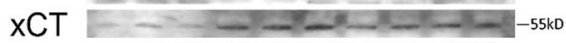

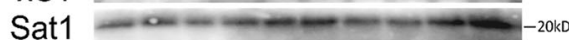

$\beta$-actin

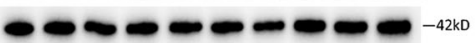

C

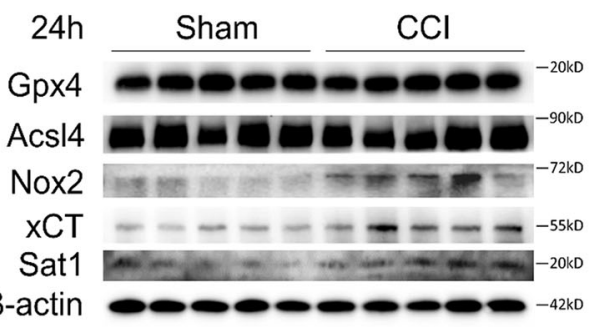

D

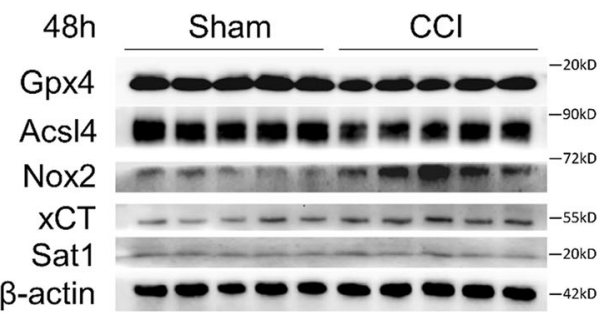

E

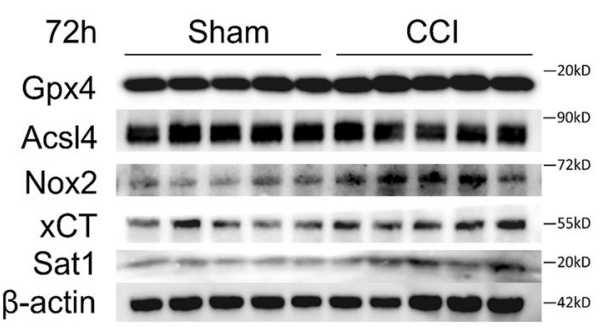

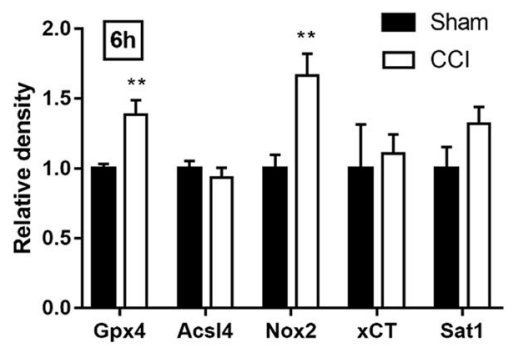
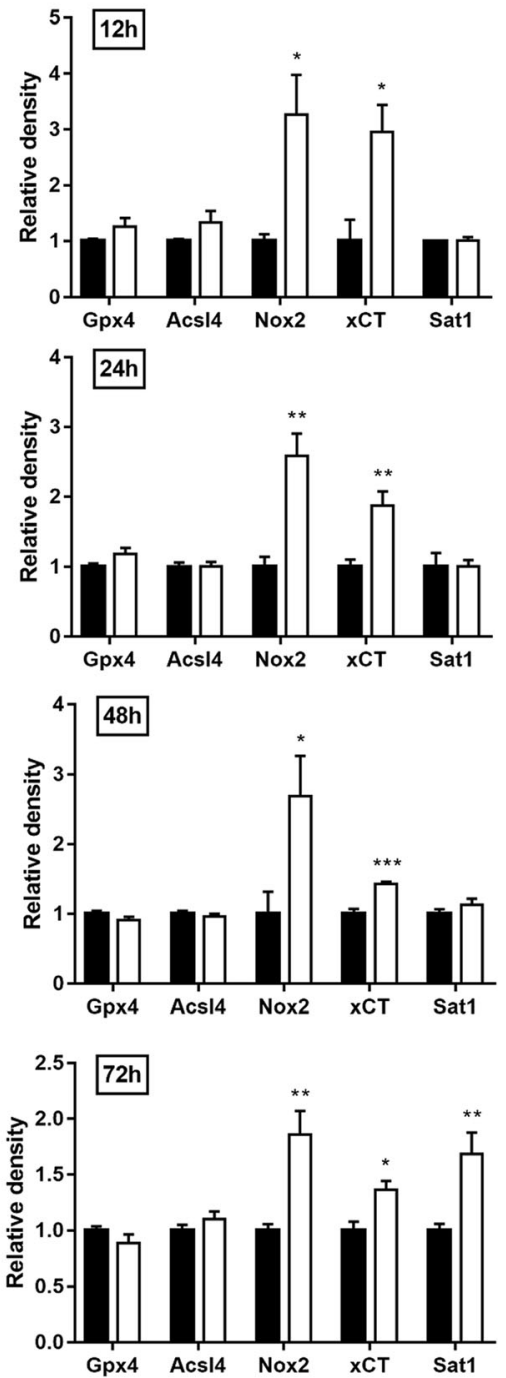

Fig. 2 The protein levels of ferroptosis-related molecules at the indicated times after CCl. Cortical expression of Gpx4, Acs/4, Nox2, xCT and Sat1 were measured in $\mathrm{CCl}$ and sham groups at $6 \mathrm{~h}(\mathbf{a}), 12 \mathrm{~h}(\mathbf{b}), 24 \mathrm{~h}(\mathbf{c}), 48 \mathrm{~h}(\mathbf{d}), 72 \mathrm{~h}(\mathbf{e})$. Data are expressed as mean \pm SEM and analyzed with the student's t-test, $n=5$ per group, ${ }^{*} p<0.05,{ }^{* *} p<0.01,{ }^{* * *} p<0.001$. CCl, controlled cortical impact

transcriptional profile, GSE79441 from http://www.ncbi.nlm. nih.gov/geo, genes with potential binding sites of miR-2125p using bioinformatics tool miRwalk [33], and molecules involved in ferroptosis $[8,9]$. One single gene, Ptgs2, emerged in all three categories (Fig. 4a) and we experimentally observed cortical Ptgs2 to be upregulated in CCI mice than the sham groups at all indicated time points (Fig. 4b).
To confirm the bioinformatics prediction, dualluciferase activity assay was applied in HT-22 and Neuro-2a cells. Firstly, the 3 ' -UTR sequence of Ptgs 2 was cloned into the pGL3 basic vector and some mismatch mutations were introduced into the seed sequences in order to create mutant reporter vectors (Fig. 4c). The luciferase activity of pGL3-Ptgs2-wt 

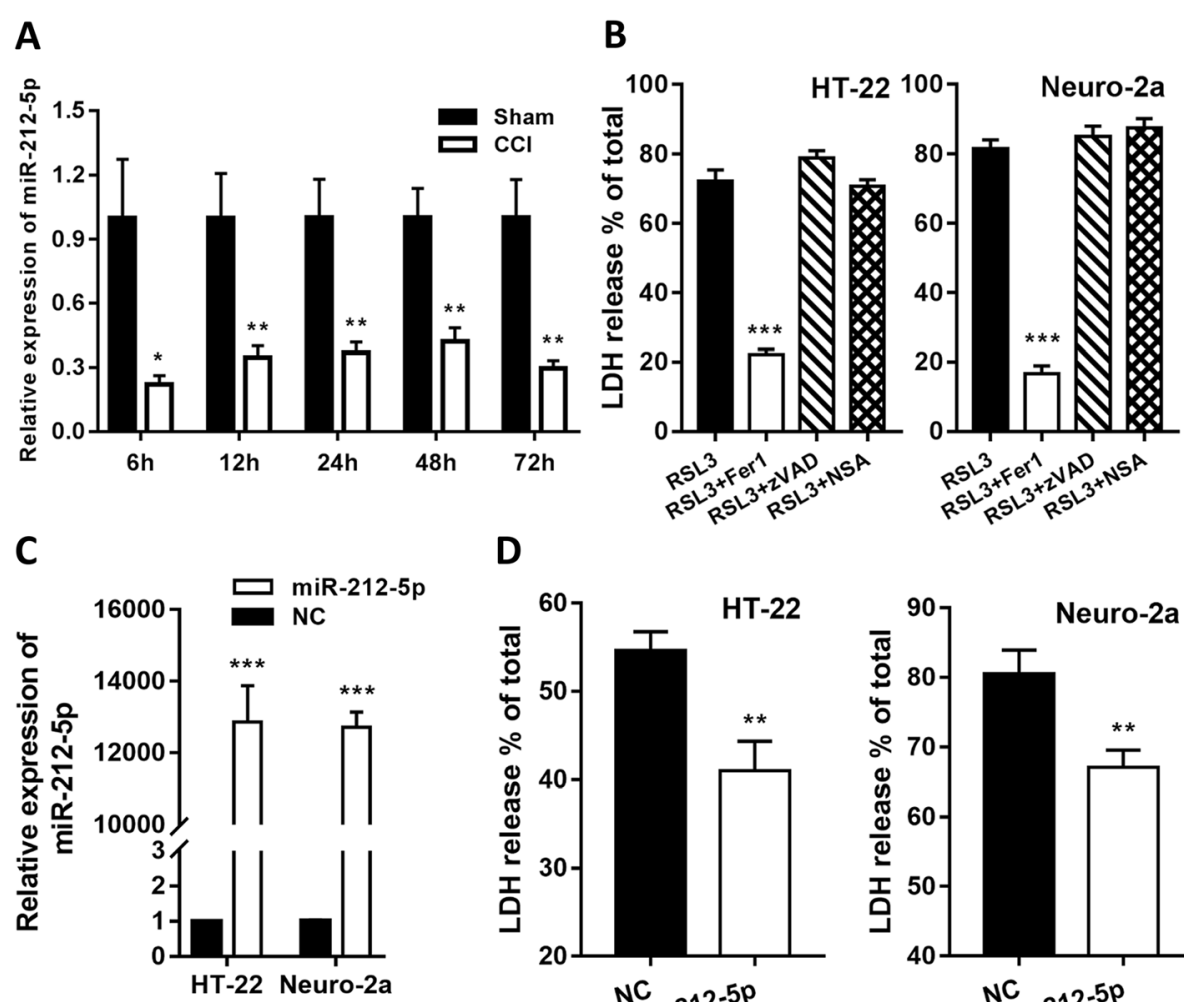

D

E
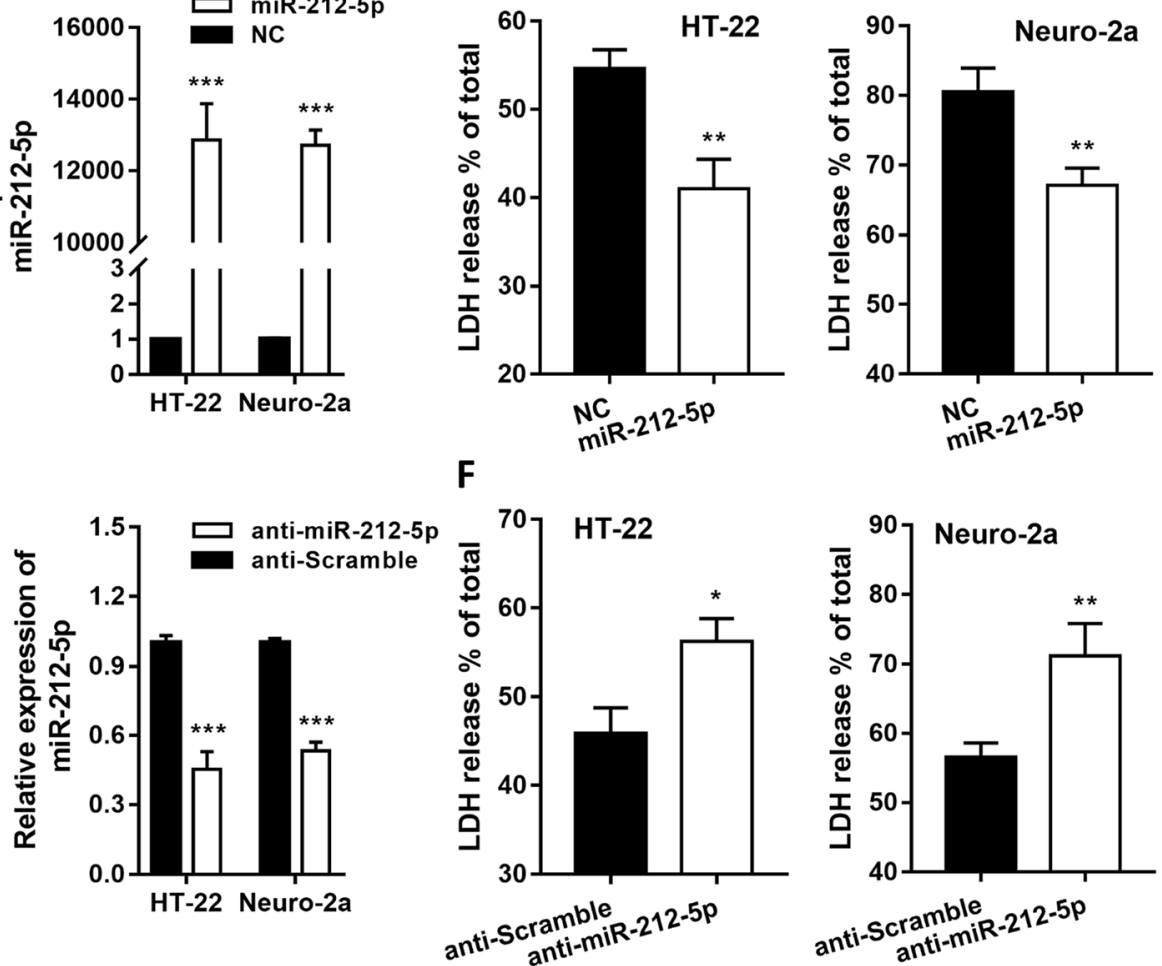

Fig. 3 miR-212-5p was constantly downregulated after CCl and negatively regulated ferroptosis in neuronal cell lines. a Quantitative RT-PCR showing the relative expression levels of miR-212-5p in the cortex at $6 h, 12 h, 1 d, 2 d, 3 d$ after injury ( $n=9$ for each group). $\mathbf{b}$ The HT-22 and Neuro-2a cells were treated with Rsl3 $(3 \mu \mathrm{M})$ with or without a cell death inhibitor (ferrostatin-1, $1 \mu \mathrm{M}$; zVAD-fmk, $10 \mu \mathrm{M}$; necrosulfonamide, $0.5 \mu \mathrm{M}$ ) for $24 \mathrm{~h}$. Data were analyzed using analysis of variance (ANOVA) with Tukey's post hoc test. c Overexpression of miR-212-5p suppressed Rsl3-induced cell death in HT-22 and Neuro-2a cells. $\mathbf{d}$ Inhibition of endogenous miR-212-5p enhanced Rsl3-induced cell death in HT-22 and Neuro-2a cells. Indicated cells were treated with Rsl3 $(3 \mu \mathrm{M})$ for $24 \mathrm{~h}$. The transfection efficacy of overexpression (e) or inhibition (f) was confirmed by qRT-PCR analysis. Cell death was assayed using the Cytotoxicity Detection kit. Data shown represent mean \pm SEM from three independent experiments. ${ }^{*} p<0.05,{ }^{* *} p<0.01,{ }^{* *} p<0.001$. CCl, controlled cortical impact

vector was significantly decreased by cotransfection of HT-22 and Neuro-2a cells with miR-212-5p mimic, while the administration of pGL3-Ptgs2-mt vector reversed the inhibitory effect of miR-212-5p (Fig. 4d). These findings indicate that the $3^{\prime}$-UTR of Ptgs 2 is a direct target of miR-212-5p.

Furthermore, the mRNA level of Ptgs 2 was analyzed by qRT-PCR in HT-22 and Neuro-2a cells transfected with
miR-212-5p mimic and inhibitor. We found that cells transfected with the mimic led to a significant downregulation in mRNA level of Ptgs2, while treatment with miR212-5p inhibitor conversely caused an upregulated mRNA expression of Ptgs2 (Fig. 4e and f). According to the abovementioned results, miR-212-5p regulates mRNA levels of Ptgs2 in both HT-22 and Neuro-2a cells, and suppresses the ferroptotic neuronal death partly by targeting Ptgs 2 . 

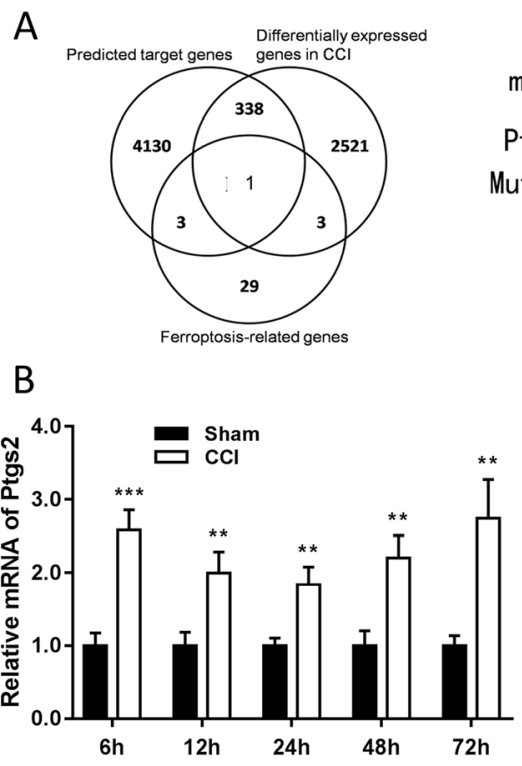

$\mathrm{E}$

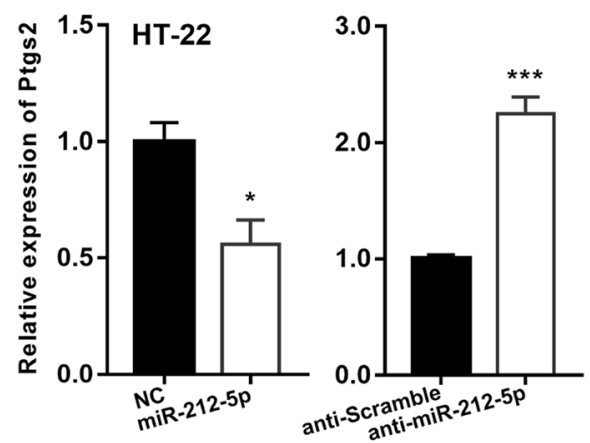

C

D

$\mathrm{F}$
miR-212-5p

Ptgs2 3'UTR

Mutant 3'UTR
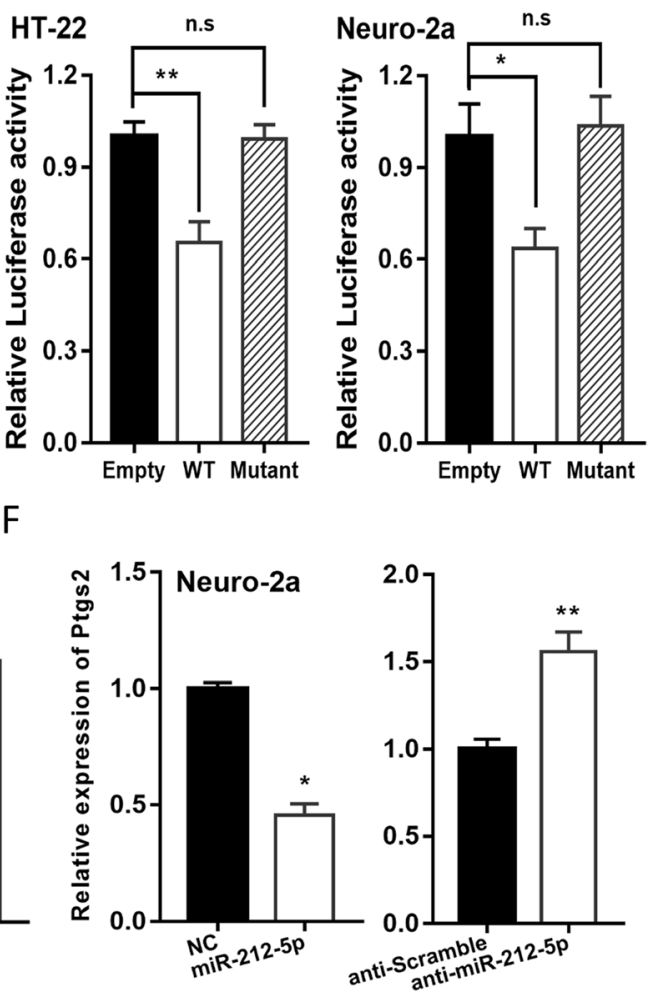

Fig. 4 miR-212-5p directly targets Ptgs2 in HT22 and Neuro-2a cell lines. Schematic diagram of strategy to discover the target gene of miR-212$5 p$ is shown in (a). b The expression of Ptgs 2 was significantly increased at all indicated time points after CCl. c Sequence alignment of miR-212$5 p$ and the $3^{\prime}-U T R$ of Ptgs2. The seed sequence of miR-212-5p and the binding sites in 3'-UTR are marked with underscores. $\mathbf{d}$ miR-212-5p overexpression inhibited the expression of $3^{\prime}-$ UTR-luciferase reporter of Ptgs2 in HT-22 and Neuro-2a cells, but the mutant construct was immune to miR-212-5p. The 3'-UTR mutants containing mismatched nucleotides are shown at the bottom. In HT-22 (e) or Neuro-2a (f) cells, miR-212-5p overexpression inhibited the expression of Ptgs2, while inhibition of miR-212-5p caused the downregulation of Ptgs 2 . Data are presented as mean \pm SEM from three independent experiments. ${ }^{*} p<0.05,{ }^{* *} p<0.01,{ }^{* * *} p<0.001$

\section{Overexpression of miR-212-5p improves performance in} Morris water maze test following $\mathrm{CCl}$ in mice

To determine the protective effect of miR-212-5p on the neurological deficits in CCI mice, the MWM test was conducted to assess spatial learning and memory ability. For this purpose, we stereotactically injected miR-212-5p agomir into the right ventricle of mice prior to TBI induction (Fig. 5a and b). MiR-212-5p agomir pretreatment remarkably shortened the escape latencies of MWM on days 11-13 in CCI mice (Fig. 5c). For the spatial probe test, frequency of passing through the platform quadrant of the pretreatment group was significantly higher than that of the CCI group (Fig. 5d) with relatively equivalent swimming speeds (Fig. 5f). Our results imply that intracerebroventricular administration of miR-212-5p may be advantageous to memory and learning improvement in CCI mice.

\section{Discussion}

As a distinct form of regulated cell death, ferroptosis has several connections to disease pathogenesis, including cancer, stroke and stress disorders [34]. Although related results are still preliminary, emerging evidence suggests that ferroptosis might also be involved in trauma-related diseases, including acute lung injury, acute kidney failure and traumatic brain injury $[8,12]$. Ferroptotic cell death lies at the intersection of amino acid, lipid and iron metabolism [8]. In our study, we observed accumulation of MDA and $\mathrm{Fe}^{2+}$ and alternation of the above-mentioned metabolism-related molecules after CCI. Our findings 


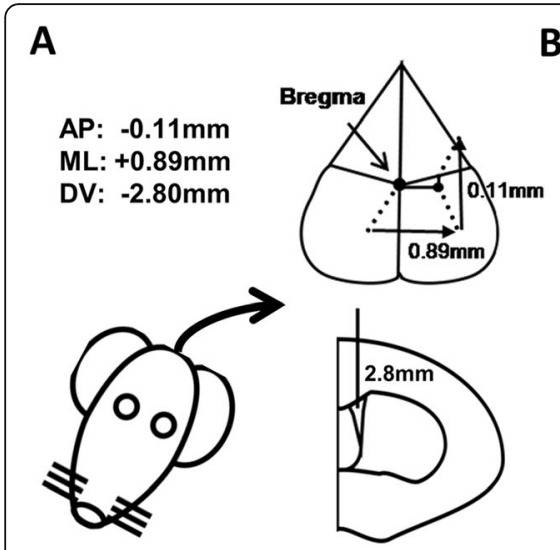

C

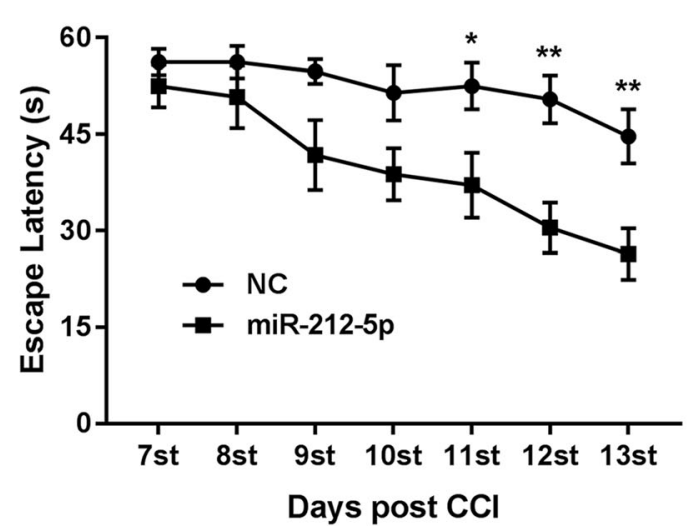

Injection of

$5 \mathrm{nmol} \mathrm{NC} / \mathrm{miR}-212-5 \mathrm{p} \quad$ The $7^{\text {th }} 1^{\text {th }}$ day for place navigation test

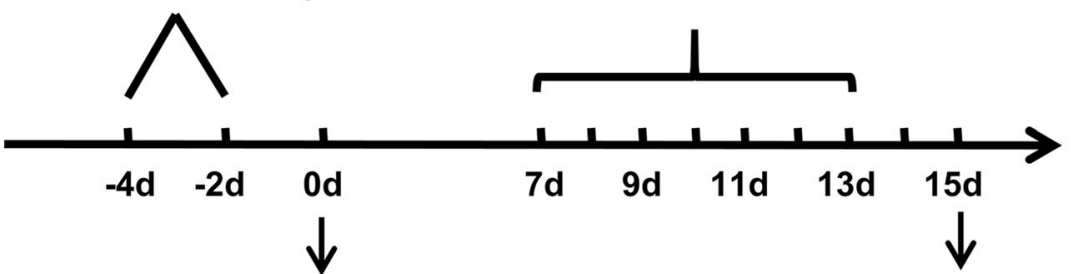

The $15^{\text {th }}$ day for spatial probe test

Fig. 5 miR-212-5p improved water maze performance after CCl in mice. a Intracerebroventricular (i.c.v.) injection site brain schematic diagram. b time course of the experiments. $\mathbf{c}$ in MWM test, mean escape latency for each group was plotted during the 7th to 13th day. Data of escape latency are performed using two-way analysis of variance (ANOVA) for repeated measures. $\mathbf{d}$ The frequency of crossing the platform was recorded on the 15th day. The speed of each mouse in the spatial probe test was recorded and shown in (e). These Data are presented as mean $\pm \operatorname{SEM}\left(n=13\right.$ for each group) and analyzed with the student's $t$-test. ${ }^{*} p<0.05$, ${ }^{* *} p<0.01$. CCl, controlled cortical impact; MWM, Morris Water Maze

together with previous reports indicate that ferroptosis is involved in the pathogenesis of CCI [35]. Many of our results are consistent with previous studies [11, 35, 36], with some exceptions. Gpx4 (converts toxic lipid hydroperoxides to non-toxic lipid alcohols) was reported to decrease after TBI [10], but in our study, its expression was barely changed compared to the sham group at all indicated time points except for the $6 \mathrm{~h}$ group in which an increased level of Gpx4 was observed. The reason underlying this difference might associate with different control groups that were used, as we compared the CCI groups with the sham operated ones instead of naive groups in which the mice were not subjected to craniotomy. Different ages or species of animals used might also contribute to the differences. As the GPx activity was shown to decrease after TBI [10], it was possibly a compensatory up-regulation of Gpx4. Another study claimed that MDA levels were highly elevated around the lesion during $72 \mathrm{~h}$ after TBI [35], but the elevation in our study was not as significant. This difference could
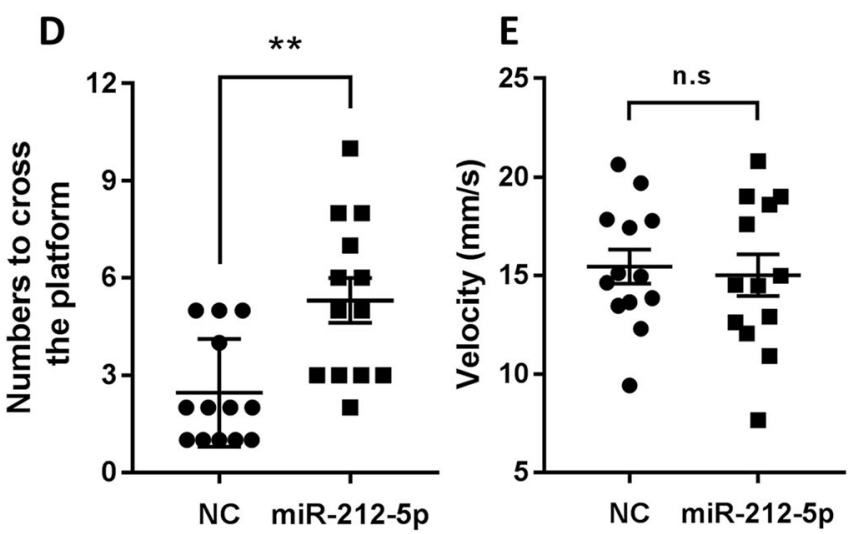

partly be attributed to the different settings of sham groups, as we utilized time points-matched sham groups instead of a single sham group. From our results, it appears that the craniotomy itself may serve a role in the pathological process after CCI, thus it may not be appropriate to compare biochemical indicators of the $\mathrm{CCI}$ group at different time points without a corresponding sham group. Interestingly, it was observed that a few molecules, such as Gpx4 and Acsl4, relevant to ferroptotic cell death, were differentially expressed only at the early time point after TBI, indicating that ferroptosis might initiate in the early stage of injury, and with the most active phase. As the master regulator of ferroptosis has not been identified [37-39], further research is needed to explore the specific marker and the comprehensive pathological contexts of ferroptosis during TBI.

Previous studies implied that miR-212 is widely involved in the neuronal system [19]. It was related to the regeneration of endothelial progenitor cells [40], integrity of the blood brain barrier [23], dendritic morphology 
[41] and oligodendrocyte differentiation [42]. It has also been implicated in addiction-related and mental diseases [43-45]. More importantly, miR-132/212 and its corresponding target mRNAs were reported to be involved in the pathogenesis of $\mathrm{AD}$, which was shown to be related to ferroptosis [24, 46, 47].

Our study, to our knowledge, is the first to report the role of miR-212-5p in the ferroptotic neuronal death after TBI, and we identified Ptgs2 as a target gene. Ptgs2, also known as cyclooxygenase-2 (Cox-2), is the key enzyme in prostaglandin biosynthesis, and acts both as a peroxidase and as a dioxygenase [48, 49]. We showed that Ptgs2 is involved in the process of ferroptosis because it was significantly upregulated after treatment with Rsl3 and erastin in mice [50-52]. These two small molecules were shown to be specific inducers of ferroptotic cell death and ideal probes to elucidate downstream regulators of ferroptosis [53-55]. As a matter of fact, cyclooxygenases can catalyze lipid oxidation $[56,57]$, however, to date, only the lipoxygenase family has been demonstrated in ferroptosis $[8,36]$. Although, the exact role of Ptgs2 in the ferroptotic cell death cascade remains to be elucidated, inhibiting Ptgs2, as induced by ferroptosis, was an effective way to alleviate cell death. According to our results, the expression of miR-212-5p after TBI was significantly downregulated at all indicated time points, and miR-212-5p suppressed ferroptosis in cell lines partly by targeting Ptgs2. These results indicate that miR-212-5p may represent a potential therapeutic target in TBI patients.

Except for acute injuries, ferroptosis has been shown to play an important role in neurodegenerative diseases [58-60], like AD, while evidence is accumulating that TBI may raise the risk of AD [61, 62]. Along with the evidence that miR-132/212 was consistently downregulated in $\mathrm{AD}$ [24], it is reasonable to speculate that miR212 may act like a bridge between TBI and neurodegenerative diseases. Moreover, there is a consensus that crosstalk widely exists between ferroptosis and other forms of regulated cell death [53, 63-66], and emerging evidence indicates that miR-212 may prevent neuron death by inhibiting other target genes, like Sirt2 [67] or participating in other pathways, like autophagy $[65,66]$ or apoptosis [63]. Further studies are urgently required to identify whether miR-212-5p is involved in any other pathologic process of TBI.

Previously, extensive studies in vivo focused on the role of miR-212-5p in tumor pathogenesis [68, 69], lipid metabolism [70, 71] and endocrine signaling axis [72, 73], while very limited data reported in nervous system. Sun et al. reported that miR-212-5p could attenuate damage and loss of dopaminergic neuron in the mouse model of Parkinson's disease [67]; Smith and the colleagues reported that miR-132/212 knockout mice have impaired memory while treatment with miR-132 rescues the memory deficits by reducing the phosphorylated tau [24]. We proved, in this study, the relationship between miR$212-5 p$ and ferroptosis in vitro. Further studies are warranted to identify the cell type-specific expression patterns of miR-212-5p and its function in vivo following CCI for a better discovery of its therapeutic value.

Collectively, our data provides sufficient evidence to confirm the involvement of ferroptosis in CCI by demonstrating that miR-212-5p negatively regulates ferroptosis partially by targeting Ptgs 2 in CCI mice. Thus, these findings implicate miR-212-5p as a potential candidate for protecting the impaired brain by attenuating ferroptosis.

\section{Abbreviations}

AD: Alzheimer's disease; AKI: Acute kidney injury; ALI: Acute lung injury; CCl: Controlled cortical impact; Cox-2: Cyclooxygenase-2; DMEM: Dulbecco's Modified Eagle's Medium; Fe ${ }^{2+}$ : Ferrous ion; GBD: Global burden of disease; ICV: Intracerebroventricular injection; LDH: Lactate dehydrogenase; MDA: Malondialdehyde; miRNAs: MicroRNAs; MWM: Morris water maze; NC: Negative control; PMSF: Phenylmethanesulfonyl fluoride; Ptgs2: Prostaglandin-endoperoxide synthase-2; qRT-PCR: quantitative realtime PCR; SEM: Standard error of the mean; TBA: Thiobarbituric acid; TBI: Traumatic brain injury; TBST: Tris-buffered saline with Tween 20; UTR: Untranslated region

\section{Acknowledgements}

We would like to thank Xuelian Zheng and Xiaolei Luo for technical support.

\section{Authors' contributions}

$X X$ and $L G$ designed the study and drafted the manuscript. $L Z, L G$ and $W L$ supervised the study. XX, YJ, YW, SC and HY performed experiments and data analysis. All authors read and approved the final manuscript.

\section{Funding}

This work was supported by the Fundamental Research Funds for the Central Universities (No. 2018SCUH0053), the Science and Technology Major Projects of Sichuan Province of China (No.2017SZDZX0013), and the Science and Technology Support Program of Sichuan Province of China (No.2016SZ0013).

\section{Availability of data and materials}

The data in our study are available from the corresponding author upon reasonable request.

\section{Ethics approval and consent to participate}

All experiments were carried out according to the policies of the Animal Care and Experimental Committee of Sichuan University.

\section{Consent for publication}

Not applicable.

\section{Competing interests}

The authors declare that they have no competing interests.

\section{Author details}

${ }^{1}$ Department of Forensic Genetics, West China School of Basic Medical Sciences \& Forensic Medicine, Sichuan University, Chengdu 610041, Sichuan, People's Republic of China. 'Laboratory of Molecular Translational Medicine, Center for Translational Medicine, Key Laboratory of Birth Defects and Related Diseases of Women and Children (Sichuan University), Ministry of Education, West China Second University Hospital, Sichuan University, Chengdu, Sichuan, People's Republic of China. ${ }^{3}$ Department of Forensic Pathology, West China School of Basic Medical Sciences \& Forensic Medicine, Sichuan University, Chengdu, Sichuan, People's Republic of China. 
Received: 2 August 2019 Accepted: 11 September 2019 Published online: 18 September 2019

\section{References}

1. Rubiano AM, Carney N, Chesnut R, Puyana JC. Global neurotrauma research challenges and opportunities. Nature. 2015;527(7578):S193-7.

2. Maas AIR, Menon DK, Adelson PD, Andelic N, Bell MJ, Belli A, et al. Traumatic brain injury: integrated approaches to improve prevention, clinical care, and research. Lancet Neurol. 2017;16(12):987-1048.

3. laccarino C, Carretta A, Nicolosi F, Morselli C. Epidemiology of severe traumatic brain injury. J Neurosurg Sci. 2018;62:535-41.

4. Majdan M, Plancikova D, Maas A, Polinder S, Feigin V, Theadom A, et al. Years of life lost due to traumatic brain injury in Europe: a cross-sectional analysis of 16 countries. PLoS Med. 2017;14(7):e1002331.

5. Cheng $P$, Yin $P$, Ning $P$, Wang $L$, Cheng $X$, Liu $Y$, et al. Trends in traumatic brain injury mortality in China, 2006-2013: a population-based longitudinal study. PLoS Med. 2017;14(7):e1002332.

6. Feigin VL, Nichols E, Alam T, Bannick MS, Beghi E, Blake N, et al. Global, regional, and national burden of neurological disorders, 1990-2016: a systematic analysis for the Global Burden of Disease Study 2016. Lancet Neurol. 2019; Available from: https:/linkinghub.elsevier.com/retrieve/pii/S147444221830499X.

7. Ved R, Zaben M. Biomarkers for traumatic brain injury. J Neurol. 2018;265(5):1241-3.

8. Stockwell BR, Friedmann Angeli JP, Bayir H, Bush Al, Conrad M, Dixon SJ, et al. Ferroptosis: a regulated cell death Nexus linking metabolism, redox biology, and disease. Cell. 2017;171:273-85.

9. Fricker M, Tolkovsky AM, Borutaite V, Coleman M, Brown GC. Neuronal cell death. Physiol Rev. 2018;98(2):813-80. https://doi.org/10.1152/physrev.00011. 2017.

10. Gaschler MM, Hu F, Feng H, Linkermann A, Min W, Stockwell BR. Determination of the subcellular localization and mechanism of action of Ferrostatins in suppressing Ferroptosis. ACS Chem Biol. 2018;13(4):1013-20.

11. Wenzel SE, Tyurina YY, Zhao J, St Croix CM, Dar HH, Mao G, et al. PEBP1 Wardens Ferroptosis by Enabling Lipoxygenase Generation of Lipid Death Signals. Cell. 2017;171(3):628-641.e26.

12. Cao JY, Dixon SJ. Mechanisms of ferroptosis. Cell Mol Life Sci. 2016;73:2195-209.

13. Lane DJR, Ayton S, Bush Al. Iron and Alzheimer's disease: an update on emerging mechanisms. J Alzheimers Dis. 2018;64(s1):S379-95. Available from: http://www. medra.org/servlet/aliasResolver?alias=iospress\&doi=10.3233/JAD-179944.

14. Becker RE, Kapogiannis D, Greig NH. Does traumatic brain injury hold the key to the Alzheimer's disease puzzle? Alzheimers Dement. 2018; 14(4):431-43. https://doi.org/10.1016/j.jalz.2017.11.007.

15. Wilson L, Stewart W, Dams-O'Connor K, Diaz-Arrastia R, Horton L, Menon $D K$, et al. The chronic and evolving neurological consequences of traumatic brain injury. Lancet Neurol. 2017;16(10):813-25. https://doi.org/10.1016/ S1474-4422(17)30279-X.

16. Rosenfeld JV, McFarlane AC, Bragge P, Armonda RA, Grimes JB, Ling GS Blast-related traumatic brain injury. Lancet Neurol. 2013;12(9):882-93.

17. Baek D, Villén J, Shin C, Camargo FD, Gygi SP, Bartel DP. The impact of microRNAs on protein output. Nature. 2008;455(7209):64-71.

18. Pan $Y B$, Sun $Z L$, Feng DF. The role of MicroRNA in traumatic brain injury. Neuroscience. 2017;367:189-99.

19. Wanet A, Tacheny A, Arnould T, Renard P. MiR-212/132 expression and functions: within and beyond the neuronal compartment. Nucleic Acids Res. 2012:40(11):4742-53.

20. Aten S, Hansen KF, Hoyt KR, Obrietan K. The miR-132/212 locus: a complex regulator of neuronal plasticity, gene expression and cognition. RNA Dis. 2016;3:e1375.

21. Hansen KF, Sakamoto K, Aten S, Snider KH, Loeser J, Hesse AM, et al. Targeted deletion of miR-132/-212 impairs memory and alters the hippocampal transcriptome. Learn Mem. 2016;23(2):61-71.

22. Hernandez-Rapp J, Smith PY, Filali M, Goupil C, Planel E, Magill ST, et al. Memory formation and retention are affected in adult miR-132/212 knockout mice. Behav Brain Res. 2015;287:15-26.

23. Burek M, König A, Lang M, Fiedler J, Oerter S, Roewer N, et al. Hypoxiainduced MicroRNA-212/132 Alter blood-brain barrier integrity through inhibition of tight junction-associated proteins in human and mouse brain microvascular endothelial cells. Transl Stroke Res. 2019. https://doi.org/10. 1007/s12975-018-0683-2.

24. Smith PY, Hernandez-Rapp J, Jolivette F, Lecours C, Bisht K, Goupil C, et al. MiR-132/212 deficiency impairs tau metabolism and promotes pathological aggregation in vivo. Hum Mol Genet. 2015;24(23):6721-35.
25. Hernandez-Rapp J, Rainone S, Goupil C, Dorval V, Smith PY, Saint-Pierre M, et al. MicroRNA-132/212 deficiency enhances A $\beta$ production and senile plaque deposition in Alzheimer's disease triple transgenic mice. Sci Rep. 2016;6:30953.

26. Harrison EB, Hochfelder CG, Lamberty BG, Meays BM, Morsey BM, Kelso ML, et al. Traumatic brain injury increases levels of miR-21 in extracellular vesicles: implications for neuroinflammation. FEBS Open Bio. 2016;6:835-46.

27. Lighthall JW. Controlled cortical impact: a New experimental brain injury model. J Neurotrauma. 2009;5(1):1-15.

28. Dean DD, Frank JA, Turtzo LC. Controlled cortical impact in the rat. Curr Protoc Neurosci. 2017;81:9.62.1-9.62.12.

29. Romine J, Gao X, Chen J. Controlled cortical impact model for traumatic brain injury. J Vis Exp. 2014;(90):e51781. https://doi.org/10.3791/51781.

30. Lyeth BG, Ray M, Hamm RJ, Schnabel J, Saady JJ, Poklis A, et al. Postinjury scopolamine administration in experimental traumatic brain injury. Brain Res. 1992;569(2):281-6.

31. Bermpohl D, You Z, Korsmeyer SJ, Moskowitz MA, Whalen MJ. Traumatic brain injury in mice deficient in bid: effects on histopathology and functional outcome. J Cereb Blood Flow Metab. 2006;26(5):625-33.

32. He J, Yang X, Men B, Wang D. Interfacial mechanisms of heterogeneous Fenton reactions catalyzed by iron-based materials: a review. J Environ Sci (China). 2016:39:97-109.

33. Sticht C, De La Torre C, Parveen A, Gretz N. Mirwalk: an online resource for prediction of microrna binding sites. PLoS One. 2018;13(10):e0206239.

34. Jiang YN, Yang SW, Zhang X, Luo LM, Zhang Z, Chen NH. Mechanism of ferroptosis and its role in neurological diseases. Chinese Pharmacol Bull. 2018;34(2):166-9.

35. Xie BS, Wang YQ, Lin Y, Mao Q, Feng JF, Gao GY, et al. Inhibition of ferroptosis attenuates tissue damage and improves long-term outcomes after traumatic brain injury in mice. CNS Neurosci Ther. 2018;25:465-75.

36. Kenny EM, Fidan E, Yang Q, Anthonymuthu TS, New LA, Meyer EA, et al. Ferroptosis contributes to neuronal death and functional outcome after traumatic brain injury. Crit Care Med. 2019;47(3):410-8.

37. Devos D, Moreau C, Kyheng M, Garçon G, Rolland AS, Blasco H, et al. A ferroptosis-based panel of prognostic biomarkers for amyotrophic lateral sclerosis. Sci Rep. 2019;9(1):2198.

38. Wu Y, Song J, Wang Y, Wang X, Culmsee C, Zhu C. The potential role of Ferroptosis in neonatal brain injury. Front Neurosci. 2019;13:115.

39. Magtanong L, Dixon SJ. Ferroptosis and brain injury. Dev Neurosci. 2019;40:382-95.

40. Hu C, Dong ZL. MicroRNA-212 promotes the recovery function and vascular regeneration of endothelial progenitor cells in mice with ischemic stroke through inactivation of the notch signaling pathway via downregulating MMP9 expression. J Cell Physiol. 2019;234(5):7090-103.

41. Mendoza-Viveros L, Chiang CK, Ong JLK, Hegazi S, Cheng AH, BouchardCannon $P$, et al. miR-132/212 modulates seasonal adaptation and dendritic morphology of the central circadian clock. Cell Rep. 2017;19(3):505-20.

42. Wang CY, Deneen B, Tzeng SF. MicroRNA-212 inhibits oligodendrocytes during maturation by down-regulation of differentiation-associated gene expression. J Neurochem. 2017;143(1):112-25.

43. Garcia-Concejo A, Jimenez-Gonzalez A, Rodriguez RE. Opioid and notch signaling pathways are reciprocally regulated through miR- 29a and miR212 expression. Biochim Biophys Acta Gen Subj. 2018;1862(12):2605-12.

44. Weigelt K, Bergink V, Burgerhout KM, Pescatori M, Wijkhuijs A, Drexhage HA. Down-regulation of inflammation-protective microRNAs 146a and 212 in monocytes of patients with postpartum psychosis. Brain Behav Immun. 2013;29:147-55

45. Keller RF, Kanlikilicer P, Dragomir A, Fan Y, Akay YM, Akay M. Investigating the effect of perinatal nicotine exposure on dopaminergic neurons in the VTA using miRNA expression profiles. IEEE Trans Nanobiosci. 2017;16(8):843-9.

46. Wang Y, Veremeyko T, Wong AHK, El Fatimy R, Wei Z, Cai W, et al. Downregulation of miR-132/212 impairs S-nitrosylation balance and induces tau phosphorylation in Alzheimer's disease. Neurobiol Aging. 2017;51:156-66.

47. Pichler S, Gu W, Hartl D, Gasparoni G, Leidinger P, Keller A, et al. The miRNome of Alzheimer's disease: consistent downregulation of the miR132/212 cluster. Neurobiol Aging. 2017;50:167.e1-167.e10.

48. Amadio P, Tarantino E, Sandrini L, Tremoli E, Barbieri SS. ProstaglandinEndoperoxide Synthase-2 deletion affects the natural trafficking of annexin A2 in monocytes and favours venous thrombosis in mice. Thromb Haemost. 2017;117(8):1486-97.

49. Hua X, Chi W, Su L, Li J, Zhang Z, Yuan X. ROS-induced oxidative injury involved in pathogenesis of fungal keratitis via p38 MAPK activation. Sci Rep. 2017;7(1):10421. 
50. Kong $Z$, Liu R, Cheng Y. Artesunate alleviates liver fibrosis by regulating ferroptosis signaling pathway. Biomed Pharmacother. 2019;109:2043-53.

51. Zhang Z, Yao Z, Wang L, Ding H, Shao J, Chen A, et al. Activation of ferritinophagy is required for the RNA-binding protein ELAVL1/HuR to regulate ferroptosis in hepatic stellate cells. Autophagy. 2018;14(12):2083-103.

52. Li Q, Han X, Lan X, Gao Y, Wan J, Durham F, et al. Inhibition of neuronal ferroptosis protects hemorrhagic brain. JCI Insight. 2017;2(7):e90777.

53. Dixon SJ, Lemberg KM, Lamprecht MR, Skouta R, Zaitsev EM, Gleason CE, et al. Ferroptosis: an iron-dependent form of nonapoptotic cell death. Cell. 2012;149(5):1060-72

54. Sui X, Zhang R, Liu S, Duan T, Zhai L, Zhang M, et al. RSL3 drives ferroptosis through GPX4 inactivation and ros production in colorectal cancer. Front Pharmacol. 2018;9:1371.

55. Hirschhorn T, Stockwell BR. The development of the concept of ferroptosis. Free Radic Biol Med. 2019:133:130-43.

56. Liu X, Moon SH, Jenkins CM, Sims HF, Gross RW. Cyclooxygenase-2 mediated oxidation of 2-Arachidonoyl-Lysophospholipids identifies unknown lipid signaling pathways. Cell Chem Biol. 2016;23(10):1217-27.

57. Bretscher P, Egger J, Shamshiev A, Trotzmuller M, Kofeler H, Carreira EM, et al. Phospholipid oxidation generates potent anti-inflammatory lipid mediators that mimic structurally related pro-resolving eicosanoids by activating Nrf2. EMBO Mol Med. 2015;7(5):593-607.

58. Hambright WS, Fonseca RS, Chen L, Na R, Ran Q. Ablation of ferroptosis regulator glutathione peroxidase 4 in forebrain neurons promotes cognitive impairment and neurodegeneration. Redox Biol. 2017;12:8-17.

59. Guiney SJ, Adlard PA, Bush Al, Finkelstein DI, Ayton S. Ferroptosis and cell death mechanisms in Parkinson's disease. Neurochem Int. 2017;104:34-48.

60. Quiles del Rey M, Mancias JD. NCOA4-mediated Ferritinophagy: a potential link to neurodegeneration. Front Neurosci. 2019;13:238.

61. IImaniemi S, Taipale H, Tanskanen A, Tiihonen J, Hartikainen S, Tolppanen AM. Incidence of head injury and traumatic brain injury among people with Alzheimer's disease. J Epidemiol Community Health. 2019;73:451-4.

62. Mohamed AZ, Cumming P, Götz J, Nasrallah F. Tauopathy in veterans with long-term posttraumatic stress disorder and traumatic brain injury. Eur J Nucl Med Mol Imaging. 2019;46:1139-51.

63. Lee Y-S, Lee D-H, Choudry HA, Bartlett DL, Lee YJ. Ferroptosis-induced endoplasmic reticulum stress: crosstalk between Ferroptosis and apoptosis. Mol Cancer Res. 2018;16:1073-6. https://doi.org/10.1158/1541-7786.MCR-18-0055.

64. Sun D, Chen X, Gu G, Wang J, Zhang J. Potential roles of mitochondriaassociated ER membranes (MAMs) in traumatic brain injury. Cell Mol Neurobiol. 2017;37:1349-57.

65. Gao M, Monian P, Pan Q, Zhang W, Xiang J, Jiang X. Ferroptosis is an autophagic cell death process. Cell Res. 2016;26(9):1021-32.

66. Kang R, Tang D. Autophagy and Ferroptosis - What's the connection? Curr Pathobiol Rep. 2017;5(2):153-9 Available from: http://www.ncbi.nIm.nih.gov/ pubmed/29038744.

67. Sun S, Han X, Li X, Song Q, Lu M, Jia M, et al. MicroRNA-212-5p prevents dopaminergic neuron death by inhibiting SIRT2 in MPTP-induced mouse model of Parkinson's disease. Front Mol Neurosci. 2018;11:381.

68. Chen W, Zhou Y, Zhi X, Ma T, Liu H, Chen BW, et al. Delivery of miR-212 by chimeric peptide-condensed supramolecular nanoparticles enhances the sensitivity of pancreatic ductal adenocarcinoma to doxorubicin. Biomaterials. 2019;192:590-600.

69. Zhang $X$, Lu L, Zhang $X$, Zhang B, Wu J. Synaptic acetylcholinesterase targeted by microRNA-212 functions as a tumor suppressor in non-small cell lung cancer. Int J Biochem Cell Biol. 2013;45:2530-40.

70. Guo Y, Yu J, Wang C, Li K, Liu B, Du Y, et al. MiR-212-5p suppresses lipid accumulation by targeting FAS and SCD1. J Mol Endocrinol. 2017;59:205-17

71. Xiao J, Bei Y, Liu J, Dimitrova-Shumkovska J, Kuang D, Zhou Q, et al. miR-212 downregulation contributes to the protective effect of exercise against nonalcoholic fatty liver via targeting FGF-21. J Cell Mol Med. 2016;20:204-16.

72. Fiedler SD, Carletti MZ, Hong X, Christenson LK. Hormonal regulation of MicroRNA expression in Periovulatory mouse mural granulosa Cells1. Biol Reprod. 2008;79:1030-7.

73. Shang J, Li J, Keller MP, Hohmeier HE, Wang Y, Feng Y, et al. Induction of miR-132 and miR-212 expression by glucagon-like peptide 1 (GLP-1) in rodent and human pancreatic $\beta$-cells. Mol Endocrinol. 2015;29:1243-53.

\section{Publisher's Note}

Springer Nature remains neutral with regard to jurisdictional claims in published maps and institutional affiliations.

\section{Ready to submit your research? Choose BMC and benefit from:}

- fast, convenient online submission

- thorough peer review by experienced researchers in your field

- rapid publication on acceptance

- support for research data, including large and complex data types

- gold Open Access which fosters wider collaboration and increased citations

- maximum visibility for your research: over $100 \mathrm{M}$ website views per year

At BMC, research is always in progress.

Learn more biomedcentral.com/submissions 